\section{Research Square}

\title{
The relationship between antenatal food insecurity, fetal and postnatal growth: findings from the South African National Income Dynamics Study
}

\author{
Abigail Joan Harper ( $\square$ abijoan@gmail.com ) \\ Alan Rothberg \\ University of the Witwatersrand

\section{Esnat Chirwa} \\ South African Medical Research Council \\ Winnie Sambu \\ University of Cape Town

\section{Sumaya Mall} \\ University of the Witwatersrand
}

University of the Witwatersrand https://orcid.org/0000-0002-0655-1108

\section{Research article}

Keywords: pregnancy, multidimensional, LBW

Posted Date: August 19th, 2020

DOI: https://doi.org/10.21203/rs.3.rs-55334/v1

License: @ (i) This work is licensed under a Creative Commons Attribution 4.0 International License. Read Full License 


\section{Abstract \\ Background}

Food insecurity during pregnancy has been associated with adverse child health outcomes including low birthweight and stunting. There are few studies that have examined the relationships between food insecurity and child health outcomes in low and middle income countries. This study aims to fill the gap by examining the relationship between food insecurity, low birthweight and stunting in children using a longitudinal sample of South African women and their children.

\section{Methods}

The primary exposure is a multidimensional, composite measure of household food insecurity that comprises three dimensions and six indicators. The primary outcome is a dichotomous measure of child LBW $(\leq 2500 \mathrm{~g})$ The secondary outcome is childhood stunting (height for age $\leq 2 S D$ of the median) and severe stunting (height for age $\leq 3 S D$ of the median) in the first five years of life. We used both unadjusted and adjusted regression models. Source data for the analysis came from the population-based, longitudinal data collected for wave one and three of the National Income Dynamics Study (2008 and 2012).

\section{Results}

Birthweight data were available for 1381 children and stunting data were available for 1444 children. The prevalence of LBW in the sample was $13.64 \%$. The prevalence of stunting and severe stunting was $16.46 \%$ and $11.87 \%$. The composite measure was not associated with low birthweight but was associated with underweight maternal BMI, a risk factor for low birthweight. Household dietary diversity, food expenditure below the Stats SA poverty line and the composite measure was associated with stunting and severe stunting in bivariate analyses. The measure was associated with severe stunting in the final model.

\section{Conclusions}

The finding that household food insecurity is associated with severe stunting for children in the first five years of life highlights the importance of adequate food and nutrition for vulnerable children in South Africa. Future studies can elucidate the relationship between antenatal food insecurity, low birthweight and other child outcomes. Policy interventions that focus on early childhood growth through alleviating food insecurity and addressing other drivers of malnutrition such as improving maternal education and dietary diversity can break the cycle of poor growth outcomes.

\section{Introduction}

Pregnancy and the postpartum period are vulnerable times for women in both high and low and middle income (LMIC) countries. In LMIC many pregnant women live in poverty and may experience a number of stressors including intimate partner violence, economic hardship and food insecurity (1-6). 
Observational epidemiological evidence from both high- and low-middle income countries on food insecurity and child health outcomes has yielded conflicting findings. A population-based case control study from the United States of America (USA) suggested an increased risk of birth defects among women who were food insecure during their pregnancies. The authors of the study hypothesized that food insecurity is associated with maternal distress as well as compromised nutrition, both of which are associated with the aetiology of birth defects (7). (Cross-sectional data from Bangladesh examined the relationship between food insecurity and infant birth size as a proxy for birthweight (12). While this study did find a significant relationship between food insecurity and infant birth size it has a number of limitations and thus the results may need to be interpreted with caution These included the subjective nature of the outcome (birth size) as well as a five-year recall period. Among a sample of older children and toddlers, a USA based retrospective cohort study linked household food insecurity to an increased risk of poor health and hospitalization in early childhood $(13,14-17)$.

These findings of previous studies described above suggest that food insecurity during antenatal or early childhood periods may be related to child health outcomes. However, several key questions remain for the field. Women living in LMIC or in high income countries with conditions of inequality are likely to experience food insecurity during their pregnancies and while some may be malnourished, this is not true for all (8-10). Food insecurity spans a spectrum from anxiety about household food supply to actual hunger in the household and little is known of how pregnant women in LMIC may experience this spectrum of food insecurity. The authors of this study sought to explore the relationship between household food insecurity during the antenatal period with birthweight and stunting in the first five years of life using data from a longitudinal population-based panel survey in South Africa.

\section{Methods}

The South African National Income Dynamics Study (SA-NIDS) is a nationally representative panel survey of households in South Africa (18). The survey which began in 2008 is conducted by the Southern Africa Labour and Development Research Unit based at the University of Cape Town, Cape Town, South Africa. To date, data from the first five waves of NIDS are available with Wave 5 concluding in 2016. The study utilizes a stratified two-stage cluster sample design to randomly select 400 of Statistics South Africa's 3000 primary sampling units (PSUs) for inclusion in the surveys (18).

\section{Ethics Approval}

The SA-NIDS was approved by the Ethics Committee of the Commerce Faculty, University of Cape Town, and the de-identified datasets are publicly available. Ethics approval for this secondary analysis was obtained from the University of the Witwatersrand Research Ethics Committee (protocol number M1909101).

The components of the secondary analysis on which this paper is based are described below:

The current paper utilized data from wave 1, 2 and 3 of NIDS. The authors obtained household level food security data and individual maternal characteristics from wave 1 household and adult questionnaires. The data from women who became pregnant between wave 1 and 2 of the study were matched with the data of their children from wave 3. Information on children was obtained from the responses to the child questionnaires which were answered on behalf of children by their mother. 
We excluded younger adolescents (age $<15)$ and older mothers (age $>44)$ because mothers on both ends of the age spectrum are more likely to experience obstetric complications and LBW and may differ systematically from the population of interest (19). Data on children were limited to children born between January 2008 and December 2011 , the commencement of data collection in wave 1 and the conclusion of data collection in wave 2. Children were aged between one and five years at the time of data collection with a mean age of 38 months.

\section{Measures}

\section{Food Insecurity}

The primary exposure during the antenatal period was the household food insecurity score, an adapted composite measure of food insecurity that is described in detail elsewhere (21). This measure covers three domains (anxiety, food quality and physical consequences) and includes six indicators (the subjective indicators of adult and child hunger and household food sufficiency and the objective indicators of dietary diversity, proportion of household expenditure on food and maternal underweight BMI). Adult and child hunger was defined as households were an adult or child never or seldom went hungry versus households were an adult or child sometimes, often or always went hungry in the past year. Household food adequacy was defined as households who reported that food consumption was more than adequate or just adequate for household needs versus less than adequate.

A household dietary diversity score (HDDS) based on 30-day recall was calculated using the Food and Agriculture Organization (FAO) guidelines. The HDDS is comprised of 32 individual food types and 12 different food groups. There is no standardized cutoff to describe low dietary diversity, but one recommendation is to use the mean HDDS score as a cutoff. The mean dietary diversity of the sample was 9.06 which indicates a fairly high number of households with diverse diets. Household scores are generated on a whole number basis and the authors therefore used a cutoff of 9 for low dietary diversity. For household food expenditure, a cutoff of expenditure above 0.6 was used to define a household as food insecure, as recommended by the FAO. While this method of measurement from household expenditure surveys (HESs) is less precise than that of food consumption surveys, it is reasonably accurate, and yields roughly the same estimates of food energy deficiency for population groups (11). A cutoff of BMl<18.5 was used to classify women as underweight per the WHO growth standards (12).

Each indicator is assigned a value of 0 or 1 , with the final score being a minimum of 0 (food secure) and a maximum of 6 (severely food insecure). Given the low percentage of underweight women, households were classified as food insecure if they scored more than one in the food quality and food anxiety domains (i.e. 2 out of 3 total domains). The food insecurity score was examined as a continuous and binary (domain insecure) variable.

\section{Covariates}

In addition to the primary exposure of the household food security score, we included variables associated with LBW and stunting in the literature in our models. These included both distal and proximate characteristics such as maternal age, height, BMI, smoking status, depression status measured using the CES-D scale (13), employment, years of education and self-reported health $(8,23,24)$. At the household level we included household size, individual food security domains, per capita food expenditure below the Stats SA Poverty level of R274 and geotype (urban, rural or traditional areas) as well as province of residence $(12,25)$. Child characteristics included gender, child's age in months and social grant status (14). 
The primary outcome is a dichotomous measure of child LBW ( $£ 2500 \mathrm{~g})$. The secondary outcome is childhood stunting (height for age $\leq 2 S D$ ) and severe stunting (height for age $\leq 3 S D$ ) in the first five years of life for children born to women between wave 1 and 2 of the NIDS study. Children's Z scores were calculated using the WHO child growth standards (12). Maternal anthropometry was collected in wave 1 of the study, while child birthweight and anthropometry were recorded in wave 3. Birthweight information was obtained from the Road to Health Card (RTHC), a child health information booklet provided by the Department of Health when women give birth (15).

\section{Statistical Analyses}

There are several steps to the analysis:

First, initial unadjusted bivariate analyses to explore covariates associated with LBW, stunting and severe stunting were conducted. Second, birthweight and height for age scores were analysed both continuously and as binary variables. Third, forward stepwise logistic regression was employed to identify potential explanatory variables associated with LBW, stunting and severe stunting. We conducted logistic regression for the final LBW model and multivariable logistic regression for the final stunting model. The latter model incorporated stunting and severe stunting. Variables included were identified from the bivariate analyses and exposures with a strength of association of $p<=0.05$ were then selected. These variables were added to the model one at a time, with those showing the strongest association added first. Those that were not significant in the stepwise model $(p>0.05)$ were removed. Last, post-stratification weights were adjusted to the age- sex-race distribution produced by Statistics South Africa based on population estimates. Analyses were based on a dataset with imputation values generated by the NIDS data team (18). All analyses were conducted using Stata 15 (Stata Corporation, College Station, TX).

A series of logistic regression models were run to compute odds ratios (ORs) with $95 \%$ confidence intervals (CI) with LBW as the primary outcome. This model aimed to determine the strength of the associations between food insecurity and other sociodemographic risk factors and LBW. Separate regression models were run to explore associations with stunting and severe stunting in children aged $0-60$ months. Significant variables were combined in a final multiple logistic regression model that included both stunting and severe stunting and nonsignificant variables excluded.

\section{Results}

\section{Sample characteristics}

We matched the data from 1685 mothers with the data from their children who were born between Wave 1 and 2 (2008-2011). A large number of children were missing anthropometry and birthweight data in wave 2 of data collection and authors therefore matched this data from wave 3 (2012). Of this sample, 1381 (82\%) of children had information on birthweight and 1444 (86\%) of children had anthropometry information. Both birthweight and anthropometry were available for 1190 (71\%) children. The mean maternal age was 25.2 years and the majority of women (86\%) belonged to the black African population group and were unemployed or not economically active (72\%). Most women were unmarried (68\%) while 31\% were married or lived with a partner. Over half $(64 \%)$ of women had given birth before, while the remainder became parents for the first time between wave 1 and 2 . Additional information on maternal characteristics is presented in Table 1. 
Information on household food adequacy and food expenditure was available for the full sample with birthweight data but between $5 \%$ and $12 \%$ of data on household dietary diversity, adult and child hunger and maternal BMI were not available for all mother-child pairs. Of the children with birthweight data, 164 (12\%) of mothers were missing anthropometry data. This limitation is further discussed at the end of this article. There was a total of 1299 complete food security scores for the sample. Scores varied between 0 and 6 with a mean of 1.40. With a cutoff of $2,79 \%$ of households were classified as food secure while the remaining $21 \%$ were food insecure. Only one household $(0.08 \%)$ had maximum scores for all indicators with a total score of 6 , but $15 \%$ of households had scores of 4 or above.

Another way to classify food insecurity using the score is to look at the scores across domains. Given the low number of underweight women in this sample, we classified households as domain insecure if they scored above 1 in the food quality and food anxiety domains (i.e. 2 out of 3 total domains). A total of $30 \%$ of households were food insecure at the domain level. This may be a better indicator of food insecurity as it produces more variation in the exposures than the sum of the individual indicators and there are more observations for the full sample. 
Table 1

Maternal and Child Socio-demographic Characteristics of the sample by birthweight $(\mathrm{N}=$ 1381)

\begin{tabular}{|c|c|c|}
\hline Maternal Variable & Categories & Overall \\
\hline \multirow[t]{3}{*}{$\operatorname{Race}(\mathrm{N}=1318)$} & Black African & $1138(86 \%)$ \\
\hline & Coloured & $112(9 \%)$ \\
\hline & Indian and White & $67(5 \%)$ \\
\hline \multirow[t]{4}{*}{ Age Intervals ( $N=1381)$} & $15-19$ & $317(23 \%)$ \\
\hline & $20-29$ & $698(51 \%)$ \\
\hline & $30-39$ & $348(25 \%)$ \\
\hline & $40+$ & $18(1 \%)$ \\
\hline \multirow[t]{3}{*}{ Geotype (N = 1381) } & Traditional & 495 (36\%) \\
\hline & Urban & $823(60 \%)$ \\
\hline & Farm & $63(4 \%)$ \\
\hline \multirow[t]{2}{*}{ Employment Status $(\mathrm{N}=1300)$} & Unemployed/not economically active & 933 (72\%) \\
\hline & Employed & 367 (28\%) \\
\hline \multirow[t]{3}{*}{ Marital Status $(\mathrm{N}=1314)$} & Married/living with partner & $408(31 \%)$ \\
\hline & Divorced or Widowed & $19(1 \%)$ \\
\hline & Never married & $887(68 \%)$ \\
\hline \multirow[t]{4}{*}{ Maternal BMI (N= 1217) } & Underweight & $69(6 \%)$ \\
\hline & Normal & $559(46 \%)$ \\
\hline & Overweight & $290(24 \%)$ \\
\hline & Obese & $299(24 \%)$ \\
\hline \multicolumn{3}{|l|}{ Child Variable } \\
\hline \multirow[t]{2}{*}{ Gender $(N=1381)$} & Male & $681(49 \%)$ \\
\hline & Female & $700(51 \%)$ \\
\hline \multirow[t]{2}{*}{ Child grant recipient $(\mathrm{N}=1381)$} & Yes & $965(70 \%)$ \\
\hline & No & $416(30 \%)$ \\
\hline
\end{tabular}


Table 2

Food security indicators and domains of the sample by birthweight $(\mathrm{N}=1066)$

\begin{tabular}{|c|c|c|c|}
\hline Indicator & Mean, SD & $\begin{array}{l}\text { Food } \\
\text { Secure }\end{array}$ & $\begin{array}{l}\text { Food } \\
\text { Insecure }\end{array}$ \\
\hline \multicolumn{4}{|l|}{ Food Quality Domain } \\
\hline Dietary Diversity (cutoff of 9) N=1304 & $\begin{array}{l}9.24 \\
(2.26)\end{array}$ & $862(66 \%)$ & $442(34 \%)$ \\
\hline $\begin{array}{l}\text { Proportion of total monthly expenditure spent on food (cutoff of } \\
0.6) \mathrm{N}=1381\end{array}$ & $\begin{array}{l}0.38 \\
(0.19)\end{array}$ & $\begin{array}{l}1182 \\
(86 \%)\end{array}$ & $199(14 \%)$ \\
\hline \multicolumn{4}{|l|}{ Anxiety and Uncertainty Domain } \\
\hline Adult Hunger in past year (Anxiety) $(\mathrm{N}=1376)$ & NA & $\begin{array}{l}1051 \\
(76 \%)\end{array}$ & $325(24 \%)$ \\
\hline Child Hunger in past year (Anxiety) $(\mathrm{N}=1282)$ & NA & $\begin{array}{l}1030 \\
(80 \%)\end{array}$ & $252(20 \%)$ \\
\hline Household food adequacy (Anxiety) $(\mathrm{N}=1059)$ & NA & $810(59 \%)$ & $571(41 \%)$ \\
\hline \multicolumn{4}{|l|}{ Physical Consequences Domain } \\
\hline Maternal BMI (cutoff of 18.5) $(\mathrm{N}=1217)$ & $\begin{array}{l}26.27 \\
(6.50)\end{array}$ & $\begin{array}{l}1157 \\
(95 \%)\end{array}$ & $60(5 \%)$ \\
\hline Food Security Score with cutoff of $2(N=1066)$ & $\begin{array}{l}1.40 \\
(1.33)\end{array}$ & $837(79 \%)$ & $229(21 \%)$ \\
\hline $\begin{array}{l}\text { Domain insecure (score }>=1 \text { in both anxiety and quality domain) } \\
(\mathrm{N}=1283)\end{array}$ & NA & $900(70 \%)$ & $383(30 \%)$ \\
\hline
\end{tabular}

This table presents the distribution of the primary exposure of food insecurity indicators at household as well as individual level. All indicators in the food quality domain as well as the anxiety and uncertainty domain are measured at the household level. BMI is the only individual indicator included in the final composite score.

Table 3

Anthropometric status of children $(\mathrm{N}=1444)$

\begin{tabular}{|c|c|c|c|c|c|c|c|c|}
\hline \multirow{2}{*}{$\begin{array}{l}\text { Height and } \\
\text { Weight for } \\
\text { Age } \\
\text { Normal } \\
\text { height }\end{array}$} & \multicolumn{2}{|c|}{$\begin{array}{l}\text { Child age } 0-24 \\
\text { months }(\mathrm{N}=35) \\
\text { Mean, SD, prevalence }\end{array}$} & \multicolumn{2}{|c|}{$\begin{array}{l}\text { Child age } 25-48 \\
\text { months }(\mathrm{N}=400) \\
\text { Mean, SD, prevalence }\end{array}$} & \multicolumn{2}{|c|}{$\begin{array}{l}\text { Child age } 49-60 \\
\text { months }(N=1009) \\
\text { Mean, SD, prevalence }\end{array}$} & \multicolumn{2}{|c|}{$\begin{array}{l}\text { All Children ( }= \\
\text { 1444) Mean, SD, } \\
\text { prevalence }\end{array}$} \\
\hline & $\begin{array}{l}0.15 \\
(1.80)\end{array}$ & $\begin{array}{l}30 \\
(85 \%)\end{array}$ & $\begin{array}{l}0.18 \\
(1.80)\end{array}$ & $\begin{array}{l}241 \\
(60 \%)\end{array}$ & $\begin{array}{l}-0.47 \\
(1.21)\end{array}$ & 764 (\%) & $\begin{array}{l}-0.21 \\
(1.47)\end{array}$ & $\begin{array}{l}1035 \\
(72 \%)\end{array}$ \\
\hline Stunted & $\begin{array}{l}-2.24 \\
(0.28)\end{array}$ & $4(11 \%)$ & $\begin{array}{l}-2.44 \\
(0.27)\end{array}$ & 73 (18\%) & $\begin{array}{l}-2.43 \\
(0.27)\end{array}$ & $161(\%)$ & $\begin{array}{l}-2.43 \\
(0.27)\end{array}$ & $\begin{array}{l}238 \\
(16 \%)\end{array}$ \\
\hline $\begin{array}{l}\text { Severely } \\
\text { Stunted }\end{array}$ & -3.11 & 1 (4\%) & $\begin{array}{l}-4.20 \\
(0.83)\end{array}$ & $86(22 \%)$ & $\begin{array}{l}-3.93 \\
(0.85)\end{array}$ & 85 (9\%) & $\begin{array}{l}-4.03 \\
(0.83)\end{array}$ & $\begin{array}{l}171 \\
(12 \%)\end{array}$ \\
\hline $\begin{array}{l}\text { Overweight } \\
\text { or Obese }\end{array}$ & $\begin{array}{l}3.04 \\
(0.92)\end{array}$ & $7(0.2 \%)$ & $\begin{array}{l}3.00 \\
(0.78)\end{array}$ & $\begin{array}{l}115 \\
(29 \%)\end{array}$ & $\begin{array}{l}2.97 \\
(0.85)\end{array}$ & $\begin{array}{l}172 \\
(17 \%)\end{array}$ & $\begin{array}{l}3.00 \\
(0.83)\end{array}$ & $\begin{array}{l}294 \\
(21 \%)\end{array}$ \\
\hline Wasted & -4.05 & $\begin{array}{l}1 \\
(0.03 \%)\end{array}$ & $\begin{array}{l}-3.38 \\
(0.91)\end{array}$ & $49(12 \%)$ & $\begin{array}{l}-3.22 \\
(0.81)\end{array}$ & $\begin{array}{l}36 \\
(0.04 \%)\end{array}$ & $\begin{array}{l}-3.29 \\
(0.86)\end{array}$ & $\begin{array}{l}86 \\
(6 \%)\end{array}$ \\
\hline
\end{tabular}


Anthropometry information was available for 1444 children. The prevalence of stunting and severe stunting was $16.46 \%$ and $11.87 \%$ respectively with 238 children classified as stunted and 171 as severely stunted. BMI information was missing for 64 children but a total of $21 \%$ of children were overweight or obese (BMI > 2 SD) while $6 \%$ of children were wasted (BMl<-2 SD). Of the children who were overweight and obese, a total of 120 (41\%) were simultaneously stunted or severely stunted children (Anthropometric comparisons are somewhat limited by the small number of children in the 0-24 month category. Levels of severe stunting and overweight and obesity were highest among children in the 25-48 month category and subsequently decreased as children aged.

Bivariate analyses

In unadjusted bivariate analyses, households with per capita food expenditure below the Stats SA poverty line (R274) and low dietary diversity were the two food security indicators most strongly associated with both stunting and severe stunting. Low dietary diversity increased the risk of stunting by $65 \%$ and more than doubled the risk of severe stunting. Children from households food insecure at the domain level were $42 \%$ and $81 \%$ more likely to be stunted and severely stunted. When analysed as a continuous variable, the food security score was associated with $18 \%$ and $29 \%$ increases in stunting and severe stunting respectively. Male children were more likely to be severely stunted than female children although there were no gender differences among stunted children. Each additional kilogram of birthweight was associated with a 33\% reduction in stunting but birthweight was not associated with severe stunting. Increased years of maternal education, greater maternal height and child's age in months reduced the risk of both stunting and severe stunting in this sample.

Variables associated with stunting and severe stunting were combined in a final multiple logistic regression model. To avoid collinearity between food security scores, domains and individual indicators the authors only included the composite food security score in the final model with maternal and child characteristics from the bivariate analyses including maternal height, years of education and child's age in months, gender and birthweight. This model includes only variables that remained significant for either stunting or severe stunting. Lower Maternal height was the only variable that remained significant for both stunting and severe stunting in the final model while years of maternal education and the food security score were significantly associated with severe stunting with maternal education offering a protective effect. 
Table 4

Unadjusted and adjusted measures of the effect of independent variables on stunting and severe stunting in children aged $4-58$ months $(\mathrm{N}=1444)$

\begin{tabular}{|c|c|c|c|c|}
\hline $\begin{array}{l}\text { Stunting ( } N= \\
238)\end{array}$ & $\begin{array}{l}\text { Unadjusted OR, Confidence } \\
\text { Intervals initial bivariate } \\
\text { regressions }\end{array}$ & $\begin{array}{l}p \\
\text { value }\end{array}$ & $\begin{array}{l}\text { Adjusted risk ratios, Confidence } \\
\text { Intervals multiple logistic } \\
\text { regression model }\end{array}$ & $\begin{array}{l}p \\
\text { value }\end{array}$ \\
\hline $\begin{array}{l}\text { Food Poverty } \\
\text { Line (R274) }\end{array}$ & $2.22(1.36-3.63)$ & 0.001 & & \\
\hline $\begin{array}{l}\text { Low Dietary } \\
\text { Diversity (score< } \\
\text { 9) }\end{array}$ & $1.65(1.17-2.33)$ & 0.004 & & \\
\hline $\begin{array}{l}\text { Food insecure } \\
(\text { score }>2)\end{array}$ & $1.57(1.04-1.33)$ & 0.011 & & \\
\hline $\begin{array}{l}\text { Domain food } \\
\text { insecure }\end{array}$ & $1.42(1.00-2.02)$ & 0.045 & & \\
\hline $\begin{array}{l}\text { Food security } \\
\text { score } \\
\text { (continuous) }\end{array}$ & $1.18(1.04-1.33)$ & 0.011 & & \\
\hline Birthweight in kg & $0.67(0.47-0.96)$ & 0.028 & & \\
\hline $\begin{array}{l}\text { Maternal } \\
\text { education (years) }\end{array}$ & $0.90(0.85-0.96)$ & 0.001 & & \\
\hline $\begin{array}{l}\text { Dietary Diversity } \\
\text { score } \\
\text { (continuous) }\end{array}$ & $0.90(0.84-0.97)$ & 0.004 & & \\
\hline Maternal height & $0.95(0.92-0.97)$ & 0.000 & $0.94(0.91-0.97)$ & 0.000 \\
\hline $\begin{array}{l}\text { Child's age in } \\
\text { months }\end{array}$ & $0.98(0.97-0.99)$ & 0.003 & & \\
\hline $\begin{array}{l}\text { Severe Stunting } \\
(N=171)\end{array}$ & $\begin{array}{l}\text { Unadjusted OR, Confidence } \\
\text { Intervals initial bivariate } \\
\text { regressions }\end{array}$ & $\begin{array}{l}p \\
\text { value }\end{array}$ & $\begin{array}{l}\text { Adjusted risk ratios, Confidence } \\
\text { Intervals multiple logistic } \\
\text { regression model }\end{array}$ & $\begin{array}{l}p \\
\text { value }\end{array}$ \\
\hline Food poverty line & $3.29(1.83-5.9)$ & 0.000 & & \\
\hline $\begin{array}{l}\text { Low Dietary } \\
\text { Diversity (score< } \\
\text { 9) }\end{array}$ & $2.6(1.66-4.06)$ & 0.000 & & \\
\hline Domain insecure & $1.81(1.15-2.83)$ & 0.009 & & \\
\hline $\begin{array}{l}\text { Food quality } \\
\text { domain }\end{array}$ & $1.66(1.12-2.3)$ & 0.001 & & \\
\hline Male child & $1.56(1.02-2.38)$ & 0.037 & & \\
\hline $\begin{array}{l}\text { Food insecure } \\
(\text { score }>2)\end{array}$ & $1.51(1.04-2.19)$ & 0.030 & & \\
\hline $\begin{array}{l}\text { Food anxiety } \\
\text { domain }\end{array}$ & $1.32(1.08-1.62)$ & 0.005 & & \\
\hline
\end{tabular}




\begin{tabular}{|lllll|}
\hline $\begin{array}{l}\text { Stunting (N) } \\
\text { 238) }\end{array}$ & $\begin{array}{l}\text { Unadjusted OR, Confidence } \\
\text { Intervals initial bivariate } \\
\text { regressions }\end{array}$ & $\begin{array}{l}\mathbf{p} \\
\text { value }\end{array}$ & $\begin{array}{l}\text { Adjusted risk ratios, Confidence } \\
\text { Intervals multiple logistic } \\
\text { regression model }\end{array}$ & $\begin{array}{l}\mathbf{p} \\
\text { value }\end{array}$ \\
\hline $\begin{array}{l}\text { Food security } \\
\text { score } \\
\text { (continuous) }\end{array}$ & $1.29(1.20-1.50)$ & 0.001 & $1.24(1.04-1.47)$ & 0.016 \\
\hline $\begin{array}{l}\text { Childs age in } \\
\text { months }\end{array}$ & $0.97(0.96-0.97)$ & 0.019 & & 0.005 \\
\hline $\begin{array}{l}\text { Maternal height } \\
\text { Maternal }\end{array}$ & $0.97(0.95-0.99)$ & 0.007 & $0.96(0.93-0.98)$ & 0.003 \\
education & $0.87(0.81-0.92)$ & 0.000 & $0.88(0.81-0.96)$ & \\
\hline $\begin{array}{l}\text { Dietary Diversity } \\
\text { score } \\
\text { continuous) }\end{array}$ & $0.85(0.78-0.93)$ & 0.000 & & \\
\hline
\end{tabular}

Birthweight data were obtained for a total of 1381 children. Mean birthweight was 3109 grams with a SD of 554 grams. The prevalence of LBW in the sample was $13.64 \%$ (a total of 188 babies). We included babies whose birthweight was recorded at exactly 2500 grams in our definition. In initial bivariate analyses the maternal characteristics associated with LBW included elevated maternal blood pressure $(p=0.035)$ and underweight maternal BMI $(p=0.04)$. Female infants were also $38 \%$ more likely to be LBW but this association lost significance when we adjusted for the panel design of the study. When analysed as a continuous variable, each unit increase in the food security score increased the risk of maternal underweight BMI by $66 \%(p=0.000)$ although this finding is not included in the table below. Variables that remained significant and were included in the final model were underweight maternal BMI and elevated maternal blood pressure. Stage 1 maternal blood pressure was bordering significance with a p value of 0.053 . Underweight maternal BMI was the only food security indicator associated with LBW in this sample.

Table 5

Unadjusted and adjusted measures of the effect of independent variables on low birthweight in children born between Wave 1 and 3 of NIDS

\begin{tabular}{|llllll|}
\hline $\begin{array}{l}\text { Low Birthweight } \\
\mathbf{( N = 1 3 8 1})\end{array}$ & Frequency & $\begin{array}{l}\text { Unadjusted OR, Confidence } \\
\text { Intervals initial bivariate } \\
\text { regressions }\end{array}$ & $\begin{array}{l}\mathbf{p} \\
\text { value }\end{array}$ & $\begin{array}{l}\text { Adjusted OR, } \\
\text { Confidence Intervals } \\
\text { final model }\end{array}$ & $\begin{array}{l}\mathbf{p} \\
\text { value }\end{array}$ \\
\hline $\begin{array}{l}\text { Elevated maternal } \\
\text { blood pressure }\end{array}$ & $97(6 \%)$ & $2.56(1.06-6.15)$ & 0.035 & $3.02(1.23-7.4)$ & 0.016 \\
\hline $\begin{array}{l}\text { Stage 1 maternal } \\
\text { blood pressure }\end{array}$ & & & & $1.91(0.00-3.6)$ & 0.053 \\
\hline $\begin{array}{l}\text { Underweight } \\
\text { maternal BMl } \\
18.5\end{array}$ & $101(8 \%)$ & $2.50(1.03-6.01)$ & 0.041 & $1.42(1.25-7.5)$ & 0.014 \\
\hline
\end{tabular}

\section{Discussion}

This study has revealed important findings about the relationship between food insecurity and child outcomes in the first five years of life. In summary we found that the most prevalent indicators of food insecurity were low dietary diversity and self-reported household food inadequacy. The prevalence of LBW was $13.64 \%$ while stunting 
and severe stunting were $16.46 \%$ and $11.87 \%$ respectively. The composite food security score was not directly associated with LBW, but women who were domain food insecure were 2.44 times as likely to be underweight than their counterparts, a risk factor for LBW. Elevated maternal blood pressure was also associated with LBW. Among severely stunted children, food expenditure below the food poverty line, low household dietary diversity and households that were domain insecure were the food security indicators most strongly associated with severe stunting. Among stunted children, food expenditure below the food poverty line was most strongly associated with stunting. For both stunted and severely stunted children, increased maternal height and education decreased risk as well as each additional month of child's age. In the final multiple logistic regression model, each unit increase of the food security score increased the risk of severe stunting by $24 \%$ while maternal education and height reduced the risk.

In $2015,24 \%$ of the world's LBW babies were born in sub-Saharan Africa and estimates of LBW trends noted risk factors including extremes of maternal age, obstetric complications, infectious diseases and maternal nutritional status (16). Birth attendants' recording of a newborn's weight as $2500 \mathrm{~g}$ when s/he weighs slightly below to avoid classifying as LBW is common practice and causes underestimation of the prevalence of the problem (16). The authors therefore used a cutoff of birthweight $\leq 2500 \mathrm{~g}$. The prevalence of LBW in the sample of $13.64 \%$ is closely aligned with recent cohort studies of birthweight in South Africa $(17,18)$.

Although the food security indicators were not directly associated with LBW or stunting in this sample, food insecurity may still influence these outcomes indirectly by increasing maternal risk to give birth to a LBW baby who may be subsequently more likely to experience compromised growth. Underweight maternal BMI was a risk factor for LBW although this finding is not included in Table 5. Only $5 \%$ of women in the sample were underweight while $50 \%$ were overweight or obese, indicating that food insecurity among the majority of South African women during the antenatal period is not severe enough to cause malnutrition or wasting. Among these women, it appears that the most food insecure were more likely to be underweight or normal weight. The association between LBW and underweight maternal BMI is supported by a systematic review and meta -analysis of over one million women that noted Dunderweight women were $48 \%$ more likely to give birth to a LBW infant (19). Another factor associated with LBW included elevated maternal blood pressure. Women with elevated blood pressure (systolic between 120 and $129 \mathrm{~mm} \mathrm{Hg}$ ) were more likely to give birth to a LBW baby than women with stage one or stage two hypertension which is somewhat surprising although stage 1 hypertension was bordering on significance in the final model with a $P$ value of 0.053 . This may be due to other risk factors for LBW such as preterm birth that were not included in the data. Hypertension is a risk factor that has been linked to food security, obesity and increased BMI in developing countries and may be partly attributable to a poor quality diet high in saturated fats and sugar $(27,28)$. In this sample of women, increased household dietary diversity decreased BMI as well as the risk of overweight and obesity although these results are not included in the tables. These findings highlight the complex links between food insecurity, poor quality diet and maternal overweight and obesity occurring concurrently with stunted children in the same household.

The total percentage of children in this sample who were stunted or severely stunted was $28.3 \%$. These figures are comparable to those estimated by two large population-based surveys, that found a stunting prevalence around $27 \%$ in children under the age of five in South Africa $(26,38)$. The finding that multiple food security indicators as well as the food security score were associated with both stunting and severe stunting highlights the deprivation that many South African children experience on a daily basis. While food insecurity status is not static and subject 
to change, these findings indicate that chronic household food insecurity during the antenatal period likely extends into the early years of childhood.

Studies from Kenya, India and Bangladesh have also noted the association between low dietary diversity and stunting in early childhood (20-22). Mean dietary diversity in this sample was 9.24 which indicates a fairly high number of households with diverse diets. However, the measure had a thirty day recall and this may have introduced some bias into the final scores. This is further discussed in the limitations section. In bivariate analyses of this sample the prevalence of stunting decreased as children grew older, with each additional month of age decreasing the risk of stunting by $4 \%$. This is not surprising as previous studies suggest that stunting tends to peak around 24 months and subsequently decrease (23-25). However, among severely stunted children in this sample, age did not have an effect. Our finding that short maternal stature increases the risk of stunting also corroborates previous studies that inherited maternal characteristics (a result of their own deficient fetal and early childhood environment) perpetuate stunting among their children $(26,27)$.

The finding that increased years of maternal education has a protective effect against severe stunting has been observed in multiple studies from Sub-Saharan Africa as well as Latin America (14, 28-32). An assessment of the national child support grant (CSG) observed no improvement in children's height for age scores for children receiving the child grant alone, $\mathrm{bbut}$ for children whose mothers have more than eight grades of schooling, early receipt of the grant has a large, positive impact, increasing HAZ by 0.19 standard deviations (33). This may be attributable not only to increased income for these mothers but also to better knowledge and practices around childcare and infant feeding practices as education increases. Investments in education for girls and women can empower them to make different choices for their children and improve the health of subsequent generations.

Birthweight and LBW is often a predictor of future stunting $(16,17,34)$ and we did find an association with LBW and stunting in unadjusted bivariate analyses but this did not remain when we adjusted for the panel design of the study. This is somewhat surprising as it suggests that the most severe linear growth retardation in this sample is primarily a product of a deficient growth environment and not related to prenatal pathology or inherited birth characteristics such as weight at birth.

A recent review of the evidence base around stunting noted that linear growth retardation is associated with (but does not cause) delayed child development, reduced earnings in adulthood, and chronic diseases (26). This finding is corroborated by a recent analysis of NIDS data that observed stunted children had reduced educational attainment, completed fewer grades and were more likely to fail a grade than their non-stunted counterparts (24). It is important to note the inherent problems with the defined cutoff of -2SD as nothing changes just above or below this number and it does not have a clinical or biological basis. In addition, the number of stunted children will be vastly underestimated in populations with a stunting prevalence $>2.5 \%$ as the entire HAZ distribution is shifted (26). In spite of these limitations, stunting remains a child health marker with intrinsic value as it has important long-term implications for growth and development. Furthermore, 163 (11.3\%) of children who were stunted had overweight or obese mothers. This phenomenon, whereby stunted children and overweight or obese mothers reside within the same household highlights the double burden of malnutrition that are particularly prevalent in countries undergoing a nutrition transition (35).

In South Africa, stunting rates have not changed over the past 20 years, affecting one in four children under five (36). In spite of national increases in most food security metrics as well as considerable expansion of the child care grant, the prevalence of malnutrition and stunted growth remain virtually unchanged (14). An analysis that

Page $13 / 18$ 
explored this apparent paradox noted that social grants alone are not enough to break the intergenerational transmission of malnutrition and poor health, and the amount of the child support grant is insufficient to cover even basic food needs (14).

\section{Limitations}

Our study has several limitations; data on gestational age were not available and preterm birth (a leading cause of LBW) could therefore not be included in our analyses. Our study did not use a validated measure for food insecurity but constructed a composite measure from several different indicators based on published literature $(21,46-49)$. Our study also assumed that household food security status remained more or less constant in the period between wave 1 and 3. The HDDS in this sample was relatively high with a mean score of 9.06 but it is important to bear in mind that the questionnaire had a thirty-day recall period and this may have falsely inflated the

results as the DDS does not measure the frequency or amount of consumption. For example, a household that consumed red meat once in the past thirty days would still receive a score for that food group. Households with higher per capita food expenditure were more likely to be missing maternal anthropometry information. These results are in keeping with the analysis of the NIDS wave 1 health data that noted Imissing anthropometry data for $11 \%$ of women and observed that respondents living in urban areas and wealthier households are more likely to have missing anthropometric measurements (37). This may have biased our sample to include fewer women who are food secure and could have led to an underestimation of the magnitude of difference in outcomes between children in food insecure and food secure households. In addition, information on maternal HIV status was not included in the study and this may be an important confounding factor for birth outcomes as well as food security $(38,39)$.

\section{Conclusion}

This study utilized data from a longitudinal national survey to examine the relationship between household food insecurity and child health outcomes. We found that household food insecurity, low dietary diversity and food expenditure below the food poverty line were associated with stunting and severe stunting in the first five years of life as well as maternal underweight BMI (a risk factor for LBW).

Our findings indicate that stunting and severe stunting in the first five years of life are more likely a consequence of food insecurity and other aspects of a deficient growth environment than an outcome of low birthweight or other maternal exposures during the antenatal period. Our study also finds that dietary diversity is a predictor of severe stunting and an effective proxy for food insecurity in studies that do not utilize a validated food security measure. However, improved food security alone is not a panacea for the poor growth outcomes that negatively impact so many South African children. The proximal drivers of stunting and malnutrition are complex and rooted in the broader social problems of South Africa that include high levels of poverty, food insecurity, and poor access to healthcare and sanitation services (36). At the time of writing, the world and South Africa were in the early stages of the Covid-19 pandemic and the indirect health and economic consequences were already being felt among South African children with decreased rates of hospital admissions, a decrease in routine vaccinations and an expected increase in childhood malnutrition $(40,41)$. Given the multiple vulnerabilities of the mothers in this study (i.e. $23 \%$ adolescents and $73 \%$ unemployed), the authors assume that food insecurity and its adverse consequences for early childhood health will be magnified by the current crisis. 
It will be a useful avenue for future research to try and elucidate the magnitude of effect of the various drivers associated with stunting. Interventions that address these other drivers of malnutrition, such as maternal education, childcare, breastfeeding and hygiene practices, as well as dietary quality are needed to ensure that South Africa children can reach their full growth potential.

\section{Declarations}

\section{Ethics approval and consent to participate}

This study is a secondary analysis of the National Income Dynamics Study (NIDS). Ethical approval for NIDS was granted by the University of Cape Town (UCT) Commerce Faculty Ethics Committee and this study was approved by the Humanities Research Ethics Committee at the University of the Witwatersrand Research Ethics Committee (protocol number M1909101). The NIDS data collectors administered a written informed consent process with all participants, and only proceeded with interviews once this process was complete. Adult caregivers consented on behalf of minor participants and completed questionnaires on their behalf.

\section{Consent for Publication}

Not Applicable

\section{Availability of data and materials}

Deidentified data from the South African National Income Dynamics Study (NIDS) can be accessed via the NIDS website (http://www.nids.uct.ac.za/). Alternatively, data that contains confidential information can be accessed via an application process with Datafirst at the University of Cape (www.datafirst.uct.ac.za).

\section{Competing interests}

The authors declare that they have no competing interests.

\section{Funding}

$\mathrm{AH}$ is funded by the Sheiham family/Wits programme on the social determinants of health and health inequality. The funding entails a three-year fellowship to the Wits School of Public Health with a focus on health inequality in the South African context.

\section{Authors contributions}

$\mathrm{AH}, \mathrm{SM}$ and $\mathrm{AR}$ were involved in conceptualising the study design. AH performed the analyses while EC provided statistical oversight. WS assisted with data management and merging datasets across waves. $A H, S M$, and $A R$ all contributed to writing the article. All authors read and approved the final manuscript.

\section{Publisher's Note}

Springer Nature remains neutral with regard to jurisdictional claims in published maps and institutional affiliations.

\section{References}


1. Field S, Onah M, van Heyningen T, Honikman S. Domestic and intimate partner violence among pregnant women in a low resource setting in South Africa: A facility-based, mixed methods study. BMC Womens Health. 2018;18(1):1-13.

2. $10.1016 /$ j.jad.2016.05.052

Heyningen T, Van, Myer L, Onah M, Tomlinson M, Field S, Honikman S. Antenatal depression and adversity in urban South Africa. J Affect Disord [Internet]. 2016;203:121-9. Available from:

http://dx.doi.org/10.1016/j.jad.2016.05.052.

3. Barnett W, Pellowski J, Kuo C, Koen N, Donald KA, Zar HJ, et al. Food-insecure pregnant women in South Africa: A cross-sectional exploration of maternal depression as a mediator of violence and trauma risk factors. BMJ Open. 2019;9(3):1-11.

4. Fisher J, de Mello MC, Patel V, Rahman A, Tran T, Holton S, et al. Prevalence and determinants of common perinatal mental disorders in women in low-and lower-middle-income countries: A systematic review. Bull World Health Organ. 2012;90(2):139-49.

5. 10.1007/s00127-018-1497-y

Abrahams Z, Lund C, Field S, Honikman S. Factors associated with household food insecurity and depression in pregnant South African women from a low socio-economic setting: a cross-sectional study. Soc Psychiatry Psychiatr Epidemiol [Internet]. 2018;0(0):0. Available from:

http://www.ncbi.nlm.nih.gov/pubmed/29445850\%0Ahttp://link.springer.com/10.1007/s00127-018-1497-y.

6. Hayati Rezvan P, Tomlinson M, Christodoulou J, Almirol E, Stewart J, Gordon S, et al. Intimate Partner Violence and Food Insecurity Predict Early Behavior Problems Among South African Children over 5-years Post-Birth. Child Psychiatry Hum Dev. 2020 Jul.

7. Carmichael SL, Yang W, Herring A, Abrams B, Shaw GM. Maternal food insecurity is associated with increased risk of certain birth defects. J Nutr [Internet]. 2007;137(9):2087-92. Available from:

http://www.ncbi.nlm.nih.gov/pubmed/17709447\%5Cnhttp://www.pubmedcentral.nih.gov/articlerender.fcgi? artid=PMC2063452.

8. Gross SR, Mdelsohn LA, Messito MJ. Additive Effects of Household Food Insecurity during Pregnancy and Infancy on Maternal Infant Feeding Styles and Practices. Physiol Behav. 2017;176(12):139-48.

9. Laraia B. Leung C. Murphy A. Health and Developmental Correlates of Child Food Insecurity from Pregnancy to Early Childhood. In 2013. p. 1-39.

10. Borders AEB, Grobman WA, Amsden LB, Holl JL. Chronic stress and low birth weight neonates in a low-income population of women. Obstet Gynecol. 2007;109(2 PART 1):331-8.

11. Smith LC, Subandoro A. Measuring Food Security Using Household Expenditure Surveys. Measuring Food Security Using Household Expenditure Surveys. International Food Policy Research Institute; 2007.

12. WHO. WHO Child Growth Standards. Vol. 7. Geneva: World Health Organization; 2008.

13. Radloff L. The CES-D, Scale. A Self-Report Depression. Appl Psychol Meas. 1977;1:385-400.

14. Devereux S, Waidler J. Why does malnutrition persist in South Africa despite social grants? Food Security SA Working Paper Series No. 001. 2017.

15. National Department of Health Republic of South Africa. Road to Health [Internet]. 2018. p. 1-45. Available from: https://www.westerncape.gov.za/general-publication/new-road-health-booklet-side-side-road-health.

16. $10.1016 / S 2214-109 X(18) 30565-5$

Page 16/18 
Blencowe H, Krasevec J, de Onis M, Black RE, An X, Stevens GA, et al. National, regional, and worldwide estimates of low birthweight in 2015, with trends from 2000: a systematic analysis. Lancet Glob Heal [Internet]. 2019;7(7):e849-60. Available from: http://dx.doi.org/10.1016/S2214-109X(18)30565-5.

17. Budree S, Stein DJ, Brittain K, Goddard E, Koen N, Barnett W, et al. Maternal and infant factors had a significant impact on birthweight and longitudinal growth in a South African birth cohort. Acta Paediatr Int $J$ Paediatr. 2017;106(11):1793-801.

18. Tshotetsi L, Dzikiti L, Hajison P, Feresu S. Maternal factors contributing to low birth weight deliveries in Tshwane District, South Africa. PLoS One. 2019;14(3):1-13.

19. Han Z, Mulla S, Beyene J, Liao G, McDonald SD. Maternal underweight and the risk of preterm birth and low birth weight: A systematic review and meta-analyses. Int J Epidemiol. 2011;40(1):65-101.

20. Rah JH, Akhter N, Semba RD, de Pee S, Bloem MW. Campbell a a, et al. Low dietary diversity is a predictor of child stunting in rural Bangladesh. Eur J Clin Nutr [Internet]. 2010 Dec [cited 2014 Dec 10];64(12):1393-8. Available from: http://www.ncbi.nlm.nih.gov/pubmed/20842167.

21. M'Kaibi FK, Steyn NP, Ochola SA, Du Plessis L. The relationship between agricultural biodiversity, dietary diversity, household food security, and stunting of children in rural Kenya. Food Sci Nutr. 2017;5(2):243-54.

22. Chandrasekhar S, Aguayo VM, Krishna V, Nair R. Household food insecurity and children's dietary diversity and nutrition in India. Evidence from the comprehensive nutrition survey in Maharashtra. Matern Child Nutr. 2017;13(October 2016):1-8.

23. Black RE, Allen LH, Bhutta ZA, Caulfield LE, de Onis M, Ezzati M, et al. Maternal and child undernutrition: global and regional exposures and health consequences. Lancet. 2008;371(9608):243-60.

24. Casale D, Desmond C, Richter LM. Catch-up growth in height and cognitive function: Why definitions matter. Econ Hum Biol. 2020;37.

25. Prendergast AJ, Humphrey JH. The stunting syndrome in developing countries. Paediatr Int Child Health. 2014;34(4):250-65.

26. Leroy JL, Frongillo EA. Perspective: What Does Stunting Really Mean? A Critical Review of the Evidence. Adv Nutr. 2019;10(2):196-204.

27. de Onis M, Branca F. Childhood stunting: A global perspective. Matern Child Nutr. 2016;12:12-26.

28. Willey BA, Cameron N, Norris SA, Pettifor JM, Griffiths PL. Socio-economic predictors of stunting in preschool children - A population-based study from Johannesburg and Soweto. South African Med J. 2009;99(6):450-6.

29. Casale D, Espi G, Norris SA. Estimating the pathways through which maternal education affects stunting: Evidence from an urban cohort in South Africa. Public Health Nutr. 2018;21(10):1810-8.

30. 10.1186/s12887-015-0406-8

Makoka D, Masibo PK. Is there a threshold level of maternal education sufficient to reduce child undernutrition? Evidence from Malawi, Tanzania and Zimbabwe. BMC Pediatr [Internet]. 2015;15(1):1-10. Available from: http://dx.doi.org/10.1186/s12887-015-0406-8.

31. Leroy JL, Habicht J-P, González de Cossío T, Ruel MT. Maternal Education Mitigates the Negative Effects of Higher Income on the Double Burden of Child Stunting and Maternal Overweight in Rural Mexico. J Nutr. 2014;144(5):765-70.

32. Dewey KG, Begum K. Long-term consequences of stunting in early life. Matern Child Nutr [Internet]. 2011 Oct [cited 2013 Nov 19];7 Suppl 3:5-18. Available from: http://www.ncbi.nlm.nih.gov/pubmed/21929633.

33. UNICEF

Page $17 / 18$ 
DSD SASSA. UNICEF. The South African Child Support Grant Impact Assessment: Evidence form a survey of children [Internet]. 2012. Available from:

https://www.unicef.org/evaldatabase/files/The_South_African_Child_Support_Grant_Impact_Assessment.pdf.

34. Aryastami NK, Shankar A, Kusumawardani N, Besral B, Jahari AB, Achadi E. Low birth weight was the most dominant predictor associated with stunting among children aged 12-23 months in Indonesia. BMC Nutr. 2017;3(1):1-6.

35. Mahmudiono T, Nindya TS, Andrias DR, Megatsari H, Rosenkranz RR. Household food insecurity as a predictor of stunted children and overweight/obese mothers (SCOWT) in Urban Indonesia. Nutrients. 2018;10(5).

36. Mathews S, Jamieson L, Lake L, Smith C. South African Child Gauge. South African Child Gauge 2014 [Internet]. 2014;124. Available from: .

37. Ardington C, Case A. Health. Analysis of the National Income Dynamics Study Wave 1 Dataset. NIDS Discuss Pap. 2009;(2):1-34.

38. Anema A, Vogenthaler N, Frongillo E, Kadiyala S, Weiser SD. Food insecurity and HIV/AIDS: current knowledge, gaps, and research priorities. Curr HIV/AIDS Rep. 2009;6(4):224-31.

39. Xiao PL, Zhou YB, Chen Y, Yang MX, Song XX, Shi Y, et al. Association between maternal HIV infection and low birth weight and prematurity: A meta-analysis of cohort studies. BMC Pregnancy Childbirth. 2015;15(1).

40. van Bruwaene L, Goga A, Green RJ. What are we doing to the children of South Africa under the guise of COVID-19 lockdown? South African Med J. 2020;15-6.

41. van der Berg S, Zuze L, Bridgman G. The impact of hte Coronavirus and lockdown on children's welfare in South Africa; Evidence from NIDS-CRAM Wave 1. 2020. 